\title{
Telomere Length Changes during Critical Illness: A Prospective, Observational Study
}

\author{
Benjamin Zribi ${ }^{1, *} \mathbb{C}$, Orit Uziel ${ }^{2} \mathbb{C}$, Meir Lahav $^{3}$, Ronit Mesilati Stahy ${ }^{4}$ and Pierre Singer 5 \\ 1 Department of Anesthesiology, Rabin Medical Center, Campus Beilinson, Petah Tikva 49100, Israel \\ 2 The Felsenstein Medical Research Center, Rabin Medical Center, Campus Beilinson, Petah Tikva and the \\ Sackler School of Medicine, Tel Aviv University, Petah Tikva 49100, Israel; Oritu@clalit.org.il \\ 3 Institute of Hematology, Davidoff Cancer Center, Rabin Medical Center and the Sackler School of Medicine, \\ Tel Aviv University, Petah Tikva 49100, Israel; mlahav@tauex.tau.ac.il \\ 4 The Felsenstein Medical Research Center, Rabin Medical Center, Campus Beilinson, Petah Tikva 49100, \\ Israel; ronit_mesilati@walla.co.il \\ 5 Department of General Intensive Care and Institute for Nutrition Research, Rabin Medical Center, Campus \\ Beilinson and the Sackler School of Medicine, Tel Aviv University, Petah Tikva 49100, Israel; \\ pierre.singer@gmail.com \\ * Correspondence: benjzr@gmail.com; Tel.: +972-03-9376521
}

Received: 12 August 2019; Accepted: 26 September 2019; Published: 27 September 2019

check for updates

\begin{abstract}
Objective: evaluation of telomere length change in acutely ill adult patients. Design: Blood samples were drawn on the first and seventh day of intensive care unit (ICU) stay to assess telomere length using a polymerase chain reaction (PCR)-based technique. Demographic data collected included age, weight, admission diagnosis, baseline laboratory values ( $\mathrm{pH}, \mathrm{C}$ - reactive protein (CRP), serum albumin level, white blood cell count (WBC) count, platelet count), and baseline SOFA and APACHE II scores. Additional data collected during the ICU stay included a repeated WBC count, the presence of positive blood cultures and outcome data, including death in the ICU or following discharge, whether ventilated or not at ICU discharge, and destination following discharge, i.e., medical ward or rehabilitation. Setting: General ICU in tertiary hospital. Patients: Forty patients admitted to the ICU within $72 \mathrm{~h}$ of hospital admission suffering from an acute illness were included in this prospective, observational study. Main results: Of the 40 patients studied, telomere shortening was noted in 21 , telomere lengthening in 11 , and no significant change in the other eight. The age of patients demonstrating telomere shortening was statistically significantly younger (45.4 vs. 61.5 years, $p<0.023)$ compared to those showing increased telomere length. In addition, a significant correlation was observed between the difference in telomere length and the corresponding difference in WBC count (telomere shortening was associated with a decreased WBC count and vice versa). A trend toward shortening was seen in patients with sepsis $(p=0.07)$. No significant correlations were found for any other demographic or outcome parameter and changes in telomere length. Conclusion: Changes in telomere length, both shortening and lengthening, were evident in the acute setting, but no associations between such changes with outcome were noted. Further studies in more homogeneous groups of patients appear to be warranted.
\end{abstract}

Keywords: telomeres; intensive care; acute illness; sepsis; white blood cells

\section{Introduction}

Critically ill patients hospitalized in the intensive care unit (ICU) typically develop an inflammatory, hypermetabolic state defined as the acute phase, which is associated with severe metabolic stress [1]. A common example is sepsis, which is defined as life-threatening organ dysfunction due to a dysregulated host response to infection [2], which may result in a complex proinflammatory and 
coagulant response [3-7]. This state, referred to as systemic inflammatory response syndrome (SIRS), is typically associated with the production of various labile reactive species, including gaseous mediators as well as reactive oxygen species, which play a central role in the pathophysiologic events characterizing the inflammatory response. Importantly, oxidative stress is an important pathophysiological trigger that may lead to DNA damage [8].Telomeres, located at the ends of each chromosome, are crucial genomic structures that protect chromosomes from decay, thus maintaining genomic integrity. Telomere structures are composed of 1000-2000 repeats of TTAGGG sequences in humans, coated by six-protein complexes called shelterins. These complexes protect telomeres from being recognized by cellular DNA repair mechanisms that otherwise may define them as double-strand DNA breaks that need to be repaired, resulting in end-to-end fusions and chromosomal instabilities. These structures normally undergo attrition during each cell division, so that processes such as growth and advancing age are associated with telomere shortening. The mean telomere shortening is 20-200 base pairs during each cell cycle until a critical point is reached, whereupon senescence and apoptosis of the cell follow [9]. Many biochemical, environmental, and genetic factors are currently being studied to assess their impact on telomere length. Thus, correlations have been observed between leukocyte telomere length and common age-related disorders, including atherosclerotic disease, heart failure, cancer, type 2 diabetes mellitus, and dementia, especially Alzheimer's disease [9-14]. Oxidative damage is thought to be the major environmental factor that accelerates telomere shortening, in vitro as well as in vivo [15], and shorter telomeres have been shown to correlate with increased levels of inflammation [16]. In this regard, chronic stress has been demonstrated to be an important factor contributing to telomere attrition in both animal models and cell cultures [17]. Another large study by Van den Berghe et al. [18] was performed with a critically ill pediatric population. This study included many patients $(n=644)$ and showed a correlation between telomere attrition of $6 \%$ and early parenteral nutrition administration. Inflammation is highly linked to telomere attrition as well. A recent study observed a highly variable rate of change in telomere length of PBMCs with a relatively slow average rate of telomere shortening ( $-16 \mathrm{bp} / \mathrm{year})$. This shortening was associated with a significant increase with age in three inflammation-related cytokines (interferon gamma, IL-6, and IL-10) and in anti-CMV IgG titer, which also varied widely across individuals. A positive correlative was observed between changes among different inflammatory cytokines. Since no correlation was found between telomere attrition, cytokine levels, and anti-CMV IgG, the authors concluded that age-related trajectories of telomere attrition, elevated circulating inflammatory cytokines, and anti-CMV IgG are independent, pointing to the fact that immune aging processes are complex and vary across individuals [19].

Findings from a recent small study of septic patients $(n=9)$ showed that significant reductions in telomere length may also occur over short time periods, namely over one week [20]. However, the correlation between changes of leukocyte telomere length in this acute setting of critically ill, metabolically stressed patients and outcome has not been evaluated to date. In this prospective study, we aimed to investigate any changes in telomere length occurring in the acute setting of a larger cohort of critically ill patients and study any association between such changes and the outcome.

\section{Materials and Methods}

\subsection{Study Population}

This prospective, observational study was performed in the 14-bed, general intensive care department of the Rabin Medical Center, Campus Beilinson and was approved by the local ethics committee review board, which waived the need for consent. The study was performed over the period of October 2017 until March 2018. Patients who met the following criteria were included in the study: recent hospital admission (i.e., $<72 \mathrm{~h}$ previously), a medical condition requiring ICU admission and a predicted length of ICU stay $\geq 5$ days. Patients were excluded if their age was $<18$ or $>75$ years and if they were pregnant or in the immediate postpartum period. 
Ethics approval: The study protocol was approved by Rabin Medical Center's local ethics committees and informed consent was waived. Approval number rmc-0319-11.

\subsection{Data Collection}

Demographic data collected on admission included age, weight, main admission diagnosis, and whether the patient was ventilated before admission to the ICU, and SOFA and APACHE II scores were calculated. Baseline laboratory data collected included $\mathrm{pH}, \mathrm{C}$-reactive protein (CRP-mg/dL), serum albumin $(\mathrm{g} / \mathrm{L})$, white blood cell count $(\mathrm{WBC}, \mathrm{K} / \mathrm{mcL})$, and platelet count $(\mathrm{K} / \mathrm{mcL})$. Additional data collected during the ICU admission included the presence of any positive blood cultures and the WBC count on the day of the second blood sample analysis. Outcome data included death in the ICU or following discharge (up to six months), whether the patient was ventilated at ICU discharge and destination following discharge, i.e., medical ward or rehabilitation.

Availability of Data and Materials: The datasets used and/or analyzed during the current study are available from the corresponding author upon a reasonable request.

\subsection{Telomere Length Analysis}

Telomere length was determined from two blood samples: the initial sample drawn in the first $72 \mathrm{~h}$ after hospitalization and the second after $<5$ or $>14$ days. For patients discharged before day 5 , a repeat sample was drawn and analyzed on the discharge day. The blood sample processing was as follows: $5 \mathrm{~mL}$ of blood was collected and the red blood cells (RBC) were lysed using the RBC lysis solution (Biological Industries, Beit Haemek, Israel). Isolation of genomic DNA was performed by using the DNA isolation kit for mammalian blood (Roche, Mannheim, Germany). Briefly, DNA was isolated by the salting-out procedure, washed, and precipitated by isopropanol. The DNA was resuspended in polymerase chain reaction (PCR)-grade water. The DNA concentration was measured by using the NanoDrop device (Thermo Fisher, Waltham, MA, USA).

DNA samples were analyzed for telomere length according to the method of Cawthon (2009) [21], with slight modifications. Each DNA sample was analyzed by two sets of primers detailed below, one for telomere length analysis and one for a reference gene analysis (human hemoglobin). The primers were diluted to $100 \mu \mathrm{M}$ in PCR grade water and then to $10 \mu \mathrm{M}$. DNA samples were diluted to $2.5 \mathrm{ng} / \mu \mathrm{L}$ in PCR grade water. The primers sequences are shown below:

telc: TGTTAGGTATCCCTATCCCTATCCCTATCCCTATCCCTAACA

telg: ACACTAAGGTTTGGGTTTGGGTTTGGGTTTGGGTTAGTGT

hbgd: GCCCGGCCCGCCGCGCCCGTCCCGCCGGAGGAGAAGTCTGCCGTT

hbgu: GGCGGCGGGCGGCGCGGGCTGGGCGGCTTCATCCACGTTCACCTTG

Reaction PCR were processed as follows: $50{ }^{\circ} \mathrm{C}$ for $2 \mathrm{~min}, 95^{\circ} \mathrm{C}$ for $5 \mathrm{~min}$, a single cycle of $94{ }^{\circ} \mathrm{C}$ for $15 \mathrm{~s}, 49^{\circ} \mathrm{C}$ for $15 \mathrm{~s} ; 40$ cycles of: $94^{\circ} \mathrm{C}$ for $15 \mathrm{~s}, 62^{\circ} \mathrm{C}$ for $10 \mathrm{~s}$ and a final stage of: $74^{\circ} \mathrm{C}$ for $15 \mathrm{~s}$. All reactions were performed using a Step One device (ABI, Waltham, MA, USA).

As a quality control for the PCR method, we used other blood samples from healthy individuals (Table S1) and obtained no variations among different independent runs (not shown). In addition, we normalized the results of the PCR reactions by running a specific DNA sample throughout the various runs.

A significant change in telomere length was defined as a $15 \%$ difference in length between the two measurements in order to take into account possible variations in telomere length [22].

\subsection{Statistical Analysis}

Continuous variables are shown as the mean \pm standard deviation(SD), while categorical variables are shown as number $(n)(\%)$. Analysis of variance was used to compare the value of continuous variables between telomere groups and the chi-square test was used for categorical variables. Survival was assessed using the Kaplan-Meier survival analysis, with the log-rank test. Pearson correlation was 
used to assess associations between continuous variables. A two-sided $p$ value $<0.05$ was considered statistically significant (SAS Software, Version 9.4, 100 SAS Campus Drive Cary, NC 27513-2414, USA).

\section{Results}

The patient selection process is shown in Figure 1.

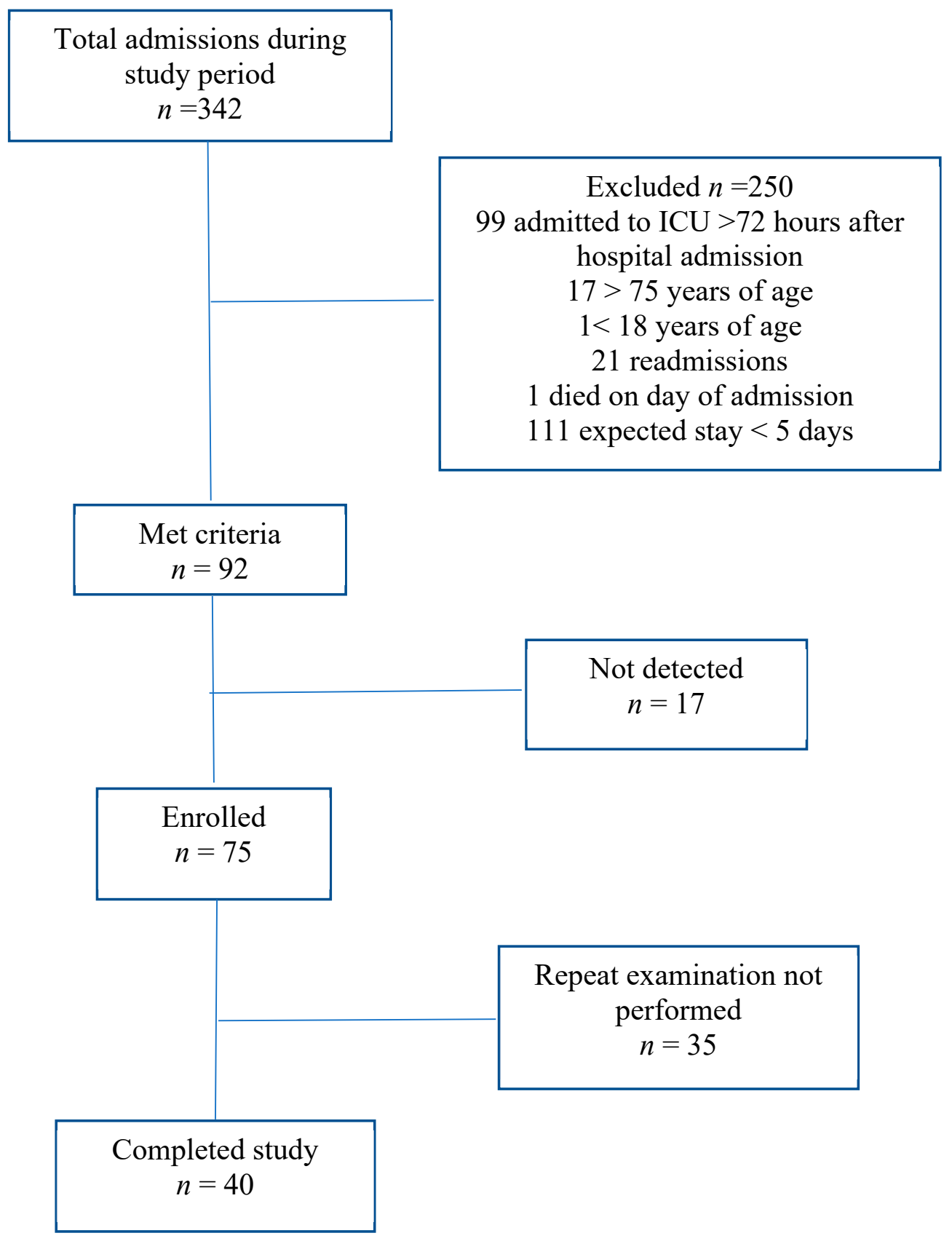

Figure 1. Flowchart of patient selection; see details in text. n-number of patients, ICU-intensive care unit.

In total, 75 patients were included in the study. Of these, a repeated sample was obtained from 40 patients (after a mean of $7.2 \pm 2.5$ days), while the remaining 35 patients with only a single measurement were excluded. Patient demographics and baseline laboratory values are shown in Table 1. 
Table 1. Characteristics and laboratory data of patients admitted to the ICU unit, mean $( \pm$ SD (standard deviation)).

\begin{tabular}{cc}
\hline Characteristic & $n=40$ \\
\hline Age (years) & $50.6( \pm 18.8)$ \\
BMI $\left(\mathrm{kg} / \mathrm{m}^{2}\right)$ & $28( \pm 6.9)$ \\
Gender (male), $n(\%)$ & $31(78 \%)$ \\
APACHE II score & $22.8( \pm 6.8)$ \\
Ventilated on admission, $n(\%)$ & $37(93 \%)$ \\
WBC count on admission (K/mcL) & $12( \pm 5.7)$ \\
Platelets count on admission (K/mcL) & $190( \pm 96)$ \\
CRP on admission (mg/dL) & $14.7( \pm 12.6)$ \\
Main diagnosis & \\
Sepsis & $8(20 \%)$ \\
Respiratory & $5(12.5 \%)$ \\
Trauma & $14(35 \%)$ \\
Organ Transplant & $3(7.5 \%)$ \\
Other & $10(25 \%)$ \\
Medical (renal failure, COPD, sepsis, CVA, & $22(55 \%)$ \\
encephalitis, liver failure, hyponatremia, post-CPR) & \\
Surgical (trauma, upper GI bleeding, liver transplant, \\
bowel perforation, necrotizing fasciitis)
\end{tabular}

BMI, body mass index, WBC, white blood cells, COPD, chronic obstructive pulmonary disease, CVA, cerebrovascular accident, CPR, cardiopulmonary resuscitation, GI, gastrointestinal.

The mean age of the patients was $50.6( \pm 18.8)$ years and the mean body mass index (BMI) was $28( \pm 6.9)$. Most patients were male $(78 \%)$, reflecting the gender mix of the ICU. The mean APACHE II and SOFA scores on admission were $22.8 \pm 6.8$ and $9.6 \pm 3.32$, respectively. Admission diagnoses were medical in $55 \%$ of cases, including renal failure, chronic obstructive pulmonary disease (COPD), sepsis, cerebrovascular accident (CVA), encephalitis, liver failure, hyponatremia, post-cardiopulmonary resuscitation (CPR), and surgical in $45 \%$ of cases including trauma, upper gastrointestinal (GI) bleeding, liver transplant, bowel perforation, and necrotizing fasciitis.

Regarding changes in telomere length, $32(80 \%)$ patients demonstrated a significant change in length, of whom 11 (27.5\%) showed an increase (from $23.7 \%$ to $100 \%$ of baseline) and 21 (52.5\%) showed a decrease (69.5\% to $17.6 \%$ of baseline). Eight patients did not show the threshold change of $15 \%$; a detailed description of telomere length is given in Table 2.

No statistically significant correlation was found in the univariate analysis with telomere length and any of the following variables: BMI, APACHE II score on admission, SOFA score on admission, main diagnosis, diagnostic group (medical vs. surgical), and any outcome variable (Table 3).

The age of patients demonstrating telomere shortening was statistically significantly younger (45.4 years vs. 61.5 years) compared with those showing increased telomere length $(p<0.023)$. A correlation was observed between a change in telomere length and a corresponding change in the repeated WBC count (i.e., telomere shortening was associated with a decreased WBC count on the second examination and telomere lengthening was associated with an increased WBC count on the second examination) with a Pearson correlation of 0.23 (Figure 2). There was no correlation between mortality and telomere length difference in any direction, as shown in Figure 3. 
Table 2. Detailed telomer length change from first sampling to second sampling.

\begin{tabular}{|c|c|c|c|}
\hline Patient Number & $\begin{array}{l}\text { T/S Ratio of First } \\
\text { Sampling }\end{array}$ & $\begin{array}{l}\text { T/S Ratio of Second } \\
\text { Sampling }\end{array}$ & $\begin{array}{l}\text { Delta between First and } \\
\text { Second Samplings }\end{array}$ \\
\hline 22 & 1 & 0.109 & -0.891 \\
\hline 24 & 1 & 1.855 & 0.855 \\
\hline 25 & 1 & 0.305 & -0.695 \\
\hline 26 & 1 & 0.746 & -0.254 \\
\hline 27 & 1 & 0.505 & -0.495 \\
\hline 28 & 1 & 0.605 & -0.395 \\
\hline 29 & 1 & 1.485 & 0.485 \\
\hline 30 & 1 & 1.237 & 0.237 \\
\hline 32 & 1 & 0.704 & -0.296 \\
\hline 34 & 1 & 0.707 & -0.293 \\
\hline 35 & 1 & 1.618 & 0.618 \\
\hline 37 & 1 & 0.785 & -0.215 \\
\hline 38 & 1 & 1.296 & 0.296 \\
\hline 39 & 1 & 1.416 & 0.416 \\
\hline 41 & 1 & 0.992 & -0.008 \\
\hline 45 & 1 & 0.626 & -0.374 \\
\hline 46 & 1 & 1.329 & 0.329 \\
\hline 47 & 1 & 2.005 & 1.005 \\
\hline 49 & 1 & 0.658 & -0.342 \\
\hline 50 & 1 & 1.6 & 0.6 \\
\hline 51 & 1 & 0.902 & -0.098 \\
\hline 52 & 1 & 0.803 & -0.197 \\
\hline 53 & 1 & 0.937 & -0.063 \\
\hline 55 & 1 & 0.541 & -0.459 \\
\hline 56 & 1 & 0.608 & -0.392 \\
\hline 57 & 1 & 1.103 & 0.103 \\
\hline 59 & 1 & 0.854 & -0.146 \\
\hline 60 & 1 & 0.82 & -0.18 \\
\hline 61 & 1 & 1.046 & 0.046 \\
\hline 62 & 1 & 1.003 & 0.003 \\
\hline 64 & 1 & 0.634 & -0.366 \\
\hline 65 & 1 & 0.867 & -0.133 \\
\hline 66 & 1 & 0.636 & -0.364 \\
\hline 68 & 1 & 0.622 & -0.378 \\
\hline 70 & 1 & 0.772 & -0.228 \\
\hline 71 & 1 & 0.594 & -0.406 \\
\hline 72 & 1 & 1.321 & 0.321 \\
\hline 73 & 1 & 0.484 & -0.516 \\
\hline 74 & 1 & 1.5943 & 0.5943 \\
\hline 75 & 1 & 0.824 & -0.176 \\
\hline
\end{tabular}

Delta, means the difference between two values. 
Table 3. Patient characteristics and telomere length changes.

\begin{tabular}{|c|c|c|c|c|}
\hline \multirow{2}{*}{ Patient Characteristic } & \multicolumn{4}{|c|}{ Delta Telomere Length (>15\% Baseline) } \\
\hline & Shorter & Unchanged & Longer & $p$-Value \\
\hline Number of patients & 21 & 8 & 11 & \\
\hline Age (years $\pm \mathrm{SD}$ ) & $45.38 *( \pm 20.84)$ & $49.50( \pm 15.63)$ & $61.45( \pm 13.53)$ & 0.0712 \\
\hline $\mathrm{BMI}\left(\mathrm{kg} / \mathrm{m}^{2} \pm \mathrm{SD}\right)$ & $29.04( \pm 7.98)$ & $28.35( \pm 8.12)$ & $25.74( \pm 2.98)$ & 0.4523 \\
\hline Male/Female & $18 / 3$ & $6 / 2$ & $7 / 4$ & 0.35813 \\
\hline APACHE-II score $( \pm \mathrm{SD})$ & $21( \pm 8)$ & $24( \pm 5)$ & $25( \pm 7)$ & 0.2562 \\
\hline SOFA score & $9( \pm 3)$ & $10( \pm 3)$ & $11( \pm 4)$ & 0.3959 \\
\hline $\mathrm{WBC}$ count $(\mathrm{K} / \mathrm{mcL} \pm \mathrm{SD})$ & $12.2( \pm 6.5)$ & $11.6( \pm 5)$ & $11.8( \pm 5.3)$ & 0.9557 \\
\hline Platelet count $(K / m c L \pm S D)$ & $203( \pm 94)$ & $201( \pm 131)$ & $156( \pm 76)$ & 0.4128 \\
\hline $\mathrm{CRP}$ & $16( \pm 13.3)$ & $15.5( \pm 12.4)$ & $11.6( \pm 13.1)$ & 0.7066 \\
\hline Albumin & $3( \pm 0.9)$ & $2.8( \pm 0.9)$ & $3( \pm 0.6)$ & 0.8334 \\
\hline $\mathrm{pH}$ & $7.3( \pm 0.11)$ & $7.25( \pm 0.12)$ & $7.31( \pm 0.11)$ & 0.4361 \\
\hline Ventilated on admission & $21 / 21$ & $7 / 8$ & 9/11 & 0.14956 \\
\hline Admission diagnosis & & & & 0.48791 \\
\hline trauma & 9 & 2 & 3 & \\
\hline sepsis & 6 & 1 & 1 & \\
\hline respiratory & 3 & 1 & 1 & \\
\hline transplant & 1 & 1 & 1 & \\
\hline other & 2 & 3 & 5 & \\
\hline Medical/Surgical & $10 / 11$ & $5 / 3$ & $7 / 4$ & 0.61399 \\
\hline
\end{tabular}

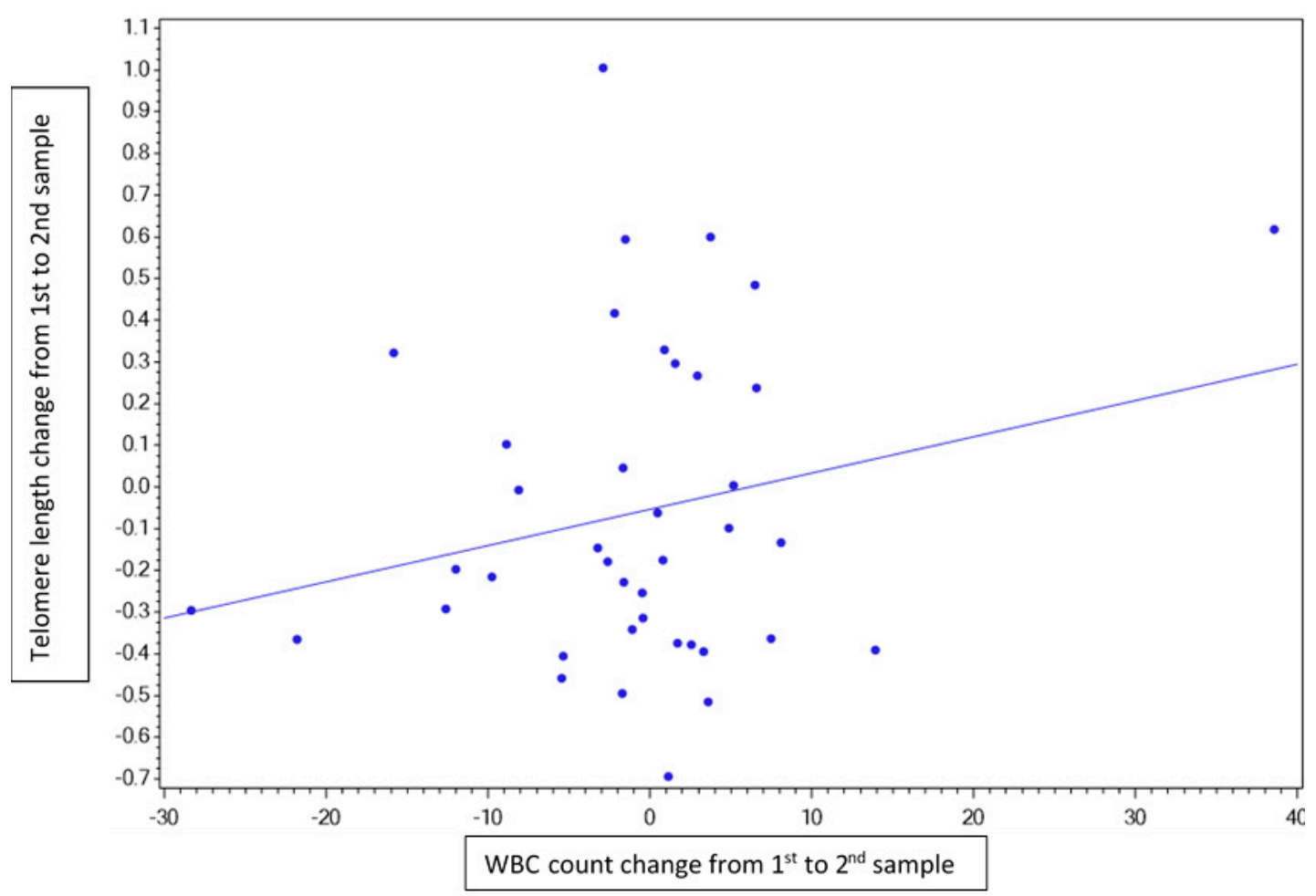

Figure 2. Pearson correlation graph. This figure demonstrates a weak link between telomere dynamics (difference in length between first and second measurement) and white blood cells (WBC) count dynamics (subtracted from WBC sampling on the day of telomere sampling). 


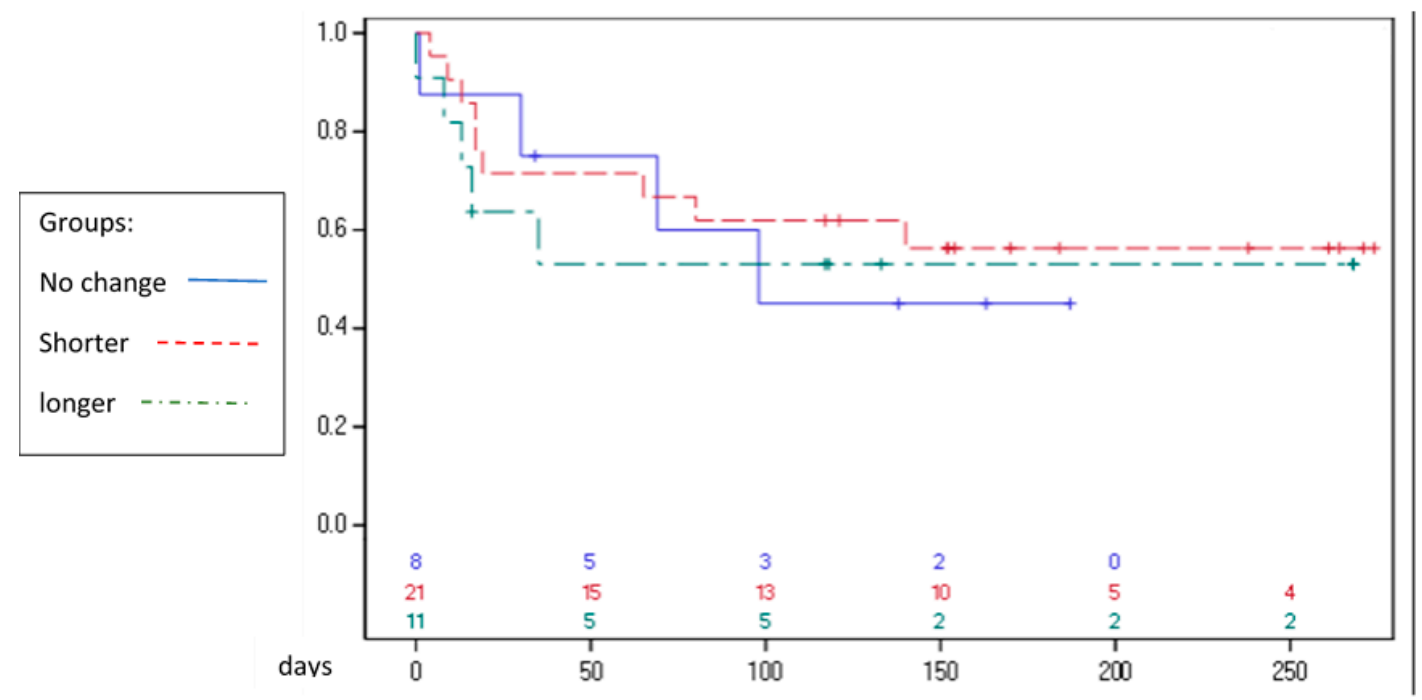

Figure 3. Kaplan-Meier curve. Follow-up of mortality from admission up to six months after study completion. Note that some patients were enrolled prior to others, hence the differential follow-up time.

\section{Discussion}

In this study, we demonstrated that significant changes in telomere length, both increases and decreases, occurred over a short time period (mean $7.2 \pm 2.5$ days) in adult, critically ill patients in the ICU. However, we were unable to demonstrate a significant correlation between telomere length changes and any outcome measure.

Telomere shortening has consistently been shown to occur in response to exogenous stress, mainly by oxidative damage $[23,24]$. Thus, for example, patients with Fanconi anemia (FA) suffer from a dysfunctional cellular response to the metabolism of oxygen, and fibroblasts from these patients demonstrate shorter telomeres and higher rates of telomere attrition compared to normal age-matched controls $[13,24,25]$. The causative connection between stress, mostly oxidative, and telomere shortening has also been shown in several other conditions, such as cyclosporine-induced nephrotoxicity [26] and in patients with hepatitis C [13]. Interestingly, a decrease in telomere shortening in human skin keratinocytes has been demonstrated following exposure to the anti-oxidative effects of pro-vitamin C [27]. Cells in the human brain also showed slowed telomere shortening after exposure to phosphorylated alpha tocopherol [28]. In an attempt to understand the mechanisms underlying oxidative stress-induced telomere shortening, Kawanishi et al. [29] followed the formation of site-specific DNA damage induced by Ultraviolet A (UVA) irradiation in the presence of endogenous photosensitizers on telomeric oligonucleotide (TTAGGG). The authors concluded that the formation of 8-oxodG at the GGG triplet in the telomere sequence induced by oxidative stress could participate in acceleration of telomere shortening [30,31].

Our findings confirm that telomere length may be altered significantly in patients with acute stress. The fact that both shortening (in the majority) and lengthening were observed suggests that multiple mechanisms may be involved in telomere length regulation in this setting and presumably through different mechanisms. Thus, while all critically ill patients may be considered to suffer from "acute metabolic stress," this definition may be too encompassing. Our finding of a correlation between changes in telomere length and the white blood cell count may suggest that acute stress leads to a free oxygen radical "hit" on the circulating white cells. It is unknown if this hit also affects the newly produced white blood cells. Our study also demonstrates a trend toward a correlation between telomere shortening and a diagnosis of sepsis. In this regard, Oliveira et al. demonstrated that induction of endotoxemia in mice resulted in significant telomere shortening in the spleen and kidney, while blood cells from patients who progressed to sepsis also exhibited a statistically significant reduction of telomere length [20]. This was associated with a concomitant increase in oxidative stress, 
which the authors hypothesized may contribute to telomere shortening in sepsis. In this regard, the shortening observed in our study cannot be explained by replicative senescence, as normal telomere attrition in healthy individuals previously measured by us is about $50 \mathrm{bp} / \mathrm{year}$ [32].

Interestingly, and in contrast to the previous study with septic patients, telomere lengthening was noted in one of our patients. The mixed behavior of telomere length in other groups of patients may imply that ongoing oxidative stress, such as typically occurs in severe sepsis, is required for telomere shortening, while transient stress, such as may be seen following trauma, may allow the white cells to recover.

Another possible explanation for the lengthening of telomeres obtained in our setting may be related to the ALT (alternative lengthening of telomeres) mechanism by which telomeres are elongated by homologous recombination-based mechanism. Whether this hypothesis is correct and why ALT occurred in the specific patients is not known at the moment and may warrant further study.

Unfortunately, to date there is no consensus regarding the definition of significant attrition. We used a cutoff of $15 \%$, which has been used by others [20]. This is higher than what was used in the largest study to date by Van den Berghe et al., who used a cutoff of $6 \%$ to describe significant attrition [18]. Further studies are required to provide a possible optimal cutoff of significant changes in telomere length.

There are several limitations to this study. Firstly, although our cohort is the largest adult cohort to examine telomere length dynamics under acute stress studied to date and included those with a high APACHE score and limited inclusion to the first 14 days, i.e., the acute phase, the cohort included a heterogeneous population, so any significant correlations may be difficult to detect. Secondly, although it is very simple and quick, the method chosen for measuring telomere length has several pitfalls. Since the sequence of telomeres is a repetitive one [(TTAGGG)n] and it is a PCR-based methodology, the primers used for the PCR reaction may attach to several places in the telomere. Therefore, the PCR product that is formed includes a population of telomere-based products of various lengths, of which we calculate the average. In spite of this, there is a clear correlation between the actual lengths of telomeres (measured in other methods including Southern blot) and the signal obtained by the PCR method. Logically, there is a direct relationship between the two: the longer the telomere is, the higher the PCR signal will be. To counteract this problem, we conducted all PCR reactions in quadraplexes and considered only results that were repeated at least twice. Importantly, the scientist who established this widely used method has proved the validity of it by comparing it to the Southern blot method (considered as the gold standard for telomere length measuring).

The other point is related to the fact that changes in telomere length can be due to a shift in leukocyte subpopulations. Therefore, an increase in total telomere length may stem from an increase in monocytes or B cells with longer telomeres. However, during a short hospitalization in the ICU the leukocyte subpopulations are not expected to change dramatically, so we have decided to ignore this issue here.

Finally, this was an observational, single-center study.

\section{Conclusions}

We have shown that changes in telomere length may occur during acute stress. However, we were unable to demonstrate a correlation between telomere behavior and any outcome measure studied, which may be related to the heterogeneity of the cohort. Additional studies focusing on specific population groups will be required to further elucidate our findings.

Supplementary Materials: The following are available online at http://www.mdpi.com/2073-4425/10/10/761/s1, Table S1: Quality control with blood samples from healthy individuals.

Author Contributions: P.S. and M.L. conceived the study design and protocol; B.Z. recruited the patients, analyzed the data, and was a major contributor in writing the manuscript; O.U. led the laboratory analysis of telomere length and was a contributor in writing the manuscript. R.M.S. was the laboratory technician and made all the 
telomere analysis; P.S. was the primary investigator and decision maker when conflicts were raised during the study, and a major contributor in writing the manuscript.

Funding: No funding was received for this study.

Acknowledgments: Cohen Jonathan-major contribution to patient selection and writing this manuscript; Rigler Merav—research coordinator; Biderman Philip—took part in patient recruitment.

Conflicts of Interest: The authors declare that they have no competing interests. There were no funders for this research hence funders had no role in the design of the study; in the collection, analyses, or interpretation of data; in the writing of the manuscript, or in the decision to publish the results.

\section{Abbreviations}

$\begin{array}{ll}\text { Abbreviation } & \text { Explanation } \\ \text { ICU } & \text { intensive care unit } \\ \text { PCR } & \text { polymerase chain reaction } \\ \text { SIRS } & \text { systemic inflammatory response syndrome } \\ \text { DNA } & \text { deoxyribonucleic acid } \\ \text { CRP } & \text { c reactive protein } \\ \text { WBC } & \text { white blood cells } \\ \text { SOFA } & \text { sequential organ failure assessment } \\ \text { APACHE } & \text { Acute Physiology and Chronic Health Evaluation } \\ \text { RBC } & \text { red blood cells } \\ \text { USA } & \text { United States of America } \\ \text { SD } & \text { standard deviation } \\ \text { BMI } & \text { body mass index } \\ \text { COPD } & \text { chronic obstructive pulmonary disease } \\ \text { CVA } & \text { cerebrovascular accident } \\ \text { CPR } & \text { cardiopulmonary resuscitation } \\ \text { GI } & \text { gastrointestinal } \\ \text { PLT } & \text { platelets } \\ \text { FA } & \text { Fanconi anemia } \\ \text { UVA } & \text { ultraviolet A } \\ \text { ALT } & \text { alternative lengthening of telomeres }\end{array}$

\section{References}

1. Darville, T.; Jacobs, R.; Giroir, B. The systemic inflammatory response syndrome (SIRS): Immunology and potential immunotherapy. Infection 1993, 21, 279-290. [CrossRef] [PubMed]

2. Shankar-Hari, M.; Phillips, G.S.; Levy, M.L.; Levy, M.; Seymour, C.W.; Liu, V.X.; Deutschman, C.S.; Angus, D.C.; Rubenfeld, G.D.; Singer, M. Developing a New Definition and Assessing New Clinical Criteria for Septic Shock. JAMA 2016, 315, 775. [CrossRef] [PubMed]

3. Fry, D.E.; Pearlstein, L.; Fulton, R.L.; Polk, H.C. Multiple system organ failure: The role of uncontrolled infection. Arch. Surg. 1980, 115, 136. [CrossRef] [PubMed]

4. Deitch, E. Multiple Organ Failure Pathophysiology and Potential Future Therapy. Ann. Surg. 1992, 216, 117-134. [CrossRef] [PubMed]

5. Salvo, I.; de Cian, W.; Musicco, M.; Langer, M.; Piadena, R.; Wölfler, A.; Montani, C.; Magni, E. The Italian SEPSIS study: Preliminary results on the incidence and evolution of SIRS, sepsis, severe sepsis and septic shock. Intensive Care Med. 1995, 21, S244-S249. [CrossRef] [PubMed]

6. Brun-Buisson, C. Incidence, risk factors, and outcome of severe sepsis and septic shock in adults. A multicenter prospective study in intensive care units. French ICU Group for Severe Sepsis. JAMA 1995, 274, 968-974. [CrossRef] [PubMed]

7. Galley, H. Oxidative stress and mitochondrial dysfunction in sepsis. BJA 2011, 107, 57-64. [CrossRef] [PubMed]

8. Dröge, W. Free Radicals in the Physiological Control of Cell Function. Physiol. Rev. 2002, 82, 47-95. [CrossRef]

9. Zhou, S. Telomeres and Telomerase: Methods and Protocols (Methods in Molecular Biology), 3rd ed.; Humana: New jersey, NJ, USA, 2017; pp. 1-13. 
10. Risques, R.; Arbeev, K.; Yashin, A.; Ukraintseva, S.V.; Martin, G.M.; Rabinovitch, P.S.; Oshima, J. Leukocyte Telomere Length Is Associated with Disability in Older, U.S. Population. J. Am. Geriatr. Soc. 2010, 58, 1289-1298. [CrossRef]

11. Strub, G.; Depcrynski, A.; Elmore, L.; Holt, S.E. Recovery from stress is a function of age and telomere length. Cell Stress Chaperones 2008, 13, 475-482. [CrossRef]

12. Adelfalk, C.; Lorenz, M.; Serra, V.; Von Zglinicki, T.; Hirsch-Kauffmann, M.; Schweiger, M. Accelerated telomere shortening in Fanconi anemia fibroblasts-A longitudinal study. FEBS Lett. 2001, 506, 22-26. [CrossRef]

13. Sekoguchi, S.; Nakajima, T.; Moriguchi, M.; Jo, M.; Nishikawa, T.; Katagishi, T.; Kimura, H.; Minami, M.; Itoh, Y.; Kagawa, K.; et al. Role of cell-cycle turnover and oxidative stress in telomere shortening and cellular senescence in patients with chronic hepatitis C. J. Gastroenterol. Hepatol. 2007, 22, 182-190. [CrossRef] [PubMed]

14. Hochstrasser, T.; Marksteiner, J.; Humpel, C. Telomere length is age-dependent and reduced in monocytes of Alzheimer patients. Exp. Gerontol. 2012, 47, 160-163. [CrossRef] [PubMed]

15. Kotrschal, A.; Ilmonen, P.; Penn, D. Stress Impacts Telomere Dynamics. Biol. Lett. 2007, 3, 128-130. [CrossRef] [PubMed]

16. Wong, J.Y.; Vivo, I.D.; Lin, X.; Fang, S.C.; Christiani, D.C. The Relationship between Inflammatory Biomarkers and Telomere Length in an Occupational Prospective Cohort Study. PLoS ONE 2014, 9, e87348. [CrossRef] [PubMed]

17. Zglinicki, T.V. Oxidative stress shortens telomeres. TIBS 2002, 27, 339-344. [CrossRef]

18. Verstraete, S.; Vanhorebeek, I.; Puffelen, E.V.; Derese, I.; Ingels, C.; Verbruggen, S.C.; Wouters, P.J.; Joosten, K.F.; Hanot, J.; Guerra, G.G.; et al. Leukocyte telomere length in paediatric critical illness: Effect of early parenteral nutrition. Crit. Care 2018, 22, 28. [CrossRef]

19. Lustig, A.; Liu, H.B.; Metter, E.J.; An, Y.; Swaby, M.A.; Elango, P.; Ferrucci, L.; Hodes, R.J.; Weng, N.-P. Telomere Shortening, Inflammatory Cytokines, and Anti-Cytomegalovirus Antibody Follow Distinct Age-Associated Trajectories in Humans. Front. Immunol. 2017, 8, 1027. [CrossRef]

20. Oliveira, N.M.; Rios, E.C. Sepsis Induces Telomere Shortening: A Potential Mechanism Responsible for Delayed Pathophysiological Events in Sepsis Survivors? Mol. Med. 2016, 22, 1. [CrossRef]

21. Cawthon, R.M. Telomere length measurement by a novel monochrome multiplex quantitative PCR method. Nucleic Acids Res. 2009, 37, e21. [CrossRef]

22. Montpetit, A.J.; Alhareeri, A.A.; Montpetit, M.; Starkweather, A.R.; Elmore, L.W.; Filler, K.; Mohanraj, L.; Burton, C.W.; Menzies, V.S.; Lyon, D.E.; et al. Telomere Length: A Review of Methods for Measurement. Nurs. Res. 2014, 63, 289-299. [CrossRef] [PubMed]

23. Stewart, S.A.; Ben-Porath, I.; Carey, V.J.; O'Connor, B.F.; Hahn, W.C.; Weinberg, R.A. Erosion of the telomeric single-strand overhang at replicative senescence. Nat. Genet. 2003, 33, 492-496. [CrossRef] [PubMed]

24. Uziel, O.; Reshef, H.; Ravid, A.; Fabian, I.; Halperin, D.; Ram, R.; Bakhanashvili, M.; Nordenberg, J.; Lahav, M. Oxidative stress causes telomere damage in Fanconi anaemia cells-A possible predisposition for malignant transformation. Br. J. Haematol. 2008, 142, 82-93. [CrossRef] [PubMed]

25. Tchirkov, A. Role of oxidative stress in telomere shortening in cultured fibroblasts from normal individuals and patients with ataxia-telangiectasia. Hum. Mol. Genet. 2003, 12, 227-232. [CrossRef]

26. Raeisi, S.; Ghorbanihaghjo, A.; Argani, H.; Dastmalchi, S.; Seifi, M.; Ghasemi, B.; Ghazizadeh, T.; Abbasi, M.M.; Karimi, P. Oxidative stress-induced renal telomere shortening as a mechanism of cyclosporine-induced nephrotoxicity. J. Biochem. Mol. Toxicol. 2018, 32, e22166. [CrossRef]

27. Yokoo, S.; Furumoto, K.; Hiyama, E.; Miwa, N. Slow-down of age-dependent telomere shortening is executed in human skin keratinocytes by hormesis-like-effects of trace hydrogen peroxide or by anti-oxidative effects of pro-vitamin C in common concurrently with reduction of intracellular oxidative stress. J. Cell Biochem. 2004, 93, 588-597. [CrossRef] [PubMed]

28. Tanaka, Y.; Moritoh, Y.; Miwa, N. Age-dependent telomere-shortening is repressed by phosphorylated $\alpha$-tocopherol together with cellular longevity and intracellular oxidative-stress reduction in human brain microvascular endotheliocytes. J. Cell Biochem. 2007, 102, 689-703. [CrossRef]

29. Kawanishi, S.; Oikawa, S. Mechanism of telomere shortening by oxidative stress. Ann. N. Y. Acad. Sci. 2004, 1019, 278-284. [CrossRef] 
30. Von Zglinicki, T.; Pilger, R.; Sitte, N. Accumulation of single-strand breaks is the major cause of telomere shortening in human fibroblasts. Free Radic. Biol. Med. 2000, 28, 64-74. [CrossRef]

31. Callen, E.; Samper, E.; Ramirez, M.J.; Creus, A.; Marcos, R.; Ortega, J.J.; Olivé, T.; Badell, I.; Blasco, M.A.; Surrallés, J. Breaks at telomeres and TRF2-independent end fusions in Fanconi anemia. Hum. Mol. Genet. 2002, 11, 439-444. [CrossRef]

32. Diker-Cohen, T.; Uziel, O.; Szyper-Kravitz, M.; Shapira, H.; Natur, A.; Lahav, M. The effect of chemotherapy on telomere dynamics: Clinical results and possible mechanisms. Leuk. Lymphoma 2013, 54, 2023-2029. [CrossRef] [PubMed]

(C) 2019 by the authors. Licensee MDPI, Basel, Switzerland. This article is an open access article distributed under the terms and conditions of the Creative Commons Attribution (CC BY) license (http://creativecommons.org/licenses/by/4.0/). 